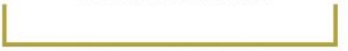

\title{
"Este dolor de estómago tengo de los palos que me da mi señora": Reflexiones en torno al trabajo doméstico de un niño esclavizado en la ciudad de Santiago de Guatemala en 1674
}

\author{
Maira Cristina Córdova Aguilar \\ Universidad Nacional Autónoma de México \\ cordova.maira@gmail.com
}

\begin{abstract}
Resumen: El propósito del trabajo es analizar las condiciones laborales y familiares que experimentaron algunos niños de origen africano en Hispanoamérica. El artículo aborda el trabajo y suicidio de Diego, un niño esclavizado originario de la ciudad de Santiago de Guatemala en la segunda mitad del siglo XVII. El objetivo del análisis es plantear diversos temas relacionados con la vida cotidiana y maltratos que vivieron estos niños en sus viviendas y centros de trabajo a partir del caso de Diego. Por un lado, se analiza la estructura familiar y laboral en que se encontraban los niños sujetos de servidumbre. Por el otro, se aborda el tema de las relaciones de convivencia y vulnerabilidad de estos niños esclavizados con su amo, compañeros de trabajo y adultos con los que vivían.
\end{abstract}

Palabras clave: esclavitud, infancia, calimbo, suicidio, Guatemala

Recibido: 1 de febrero de 2021. Aprobado: 16 de abril de 2021. 


\section{Introducción}

La población esclavizada de origen africano experimentó una diversidad de escenarios que estaban condicionados por su género, edad, trabajo, relaciones familiares o con su amo, del mismo modo que con la temporalidad y lugar que habitaron. Por tanto, cada caso tiene una particularidad. Este artículo tiene el propósito de analizar la vida de algunos niños esclavizados en el periodo colonial en Guatemala. Si bien el trabajo se basa en los testimonios de un documento judicial en que se expresa de manera parcial la vida, trabajo y muerte de un niño esclavizado, el artículo intenta mostrar y reflexionar cuáles eran las condiciones que experimentaron algunos niños desde su condición jurídica de sujeción.

El expediente, que data de 1674, está completo y contiene información sobre las pesquisas que realizaron las autoridades para conocer los motivos que llevaron a Diego a quitarse la vida. A partir de este acontecimiento, los amos, la madre y los testigos fueron llamados a declarar sobre la vida, trabajo y malos tratos que experimentaba el mulatillo. La información de este documento permite conocer algunos aspectos de la vida de niños esclavizados, como la convivencia con su familia, amo y otras personas con quienes compartían su entorno. Al margen de la información que brinda el expediente sobre la vida de Diego, un aspecto notable del caso es que se aborda el tema del suicidio. Sobre esta práctica se sabe que fue ejecutada por algunas personas esclavizadas para terminar su situación; no obstante, es significativo que este hecho lo haya llevado a cabo una persona de corta edad.

Como punto de partida señalo que este trabajo abordará -desde un enfoque de la microhistoria- la vida de los niños esclavizados de origen africano durante el periodo colonial; tema emergente e ineludible para ahondar en la labor de las personas esclavizadas, dado que sin el estudio de este sector de la población solo podemos conocer "un panorama parcial de la esclavitud en América”. ${ }^{1}$ Un aspecto que hay que precisar es que en este artículo se entiende por niños a quienes no han llegado a los siete años de edad. ${ }^{2}$ Sin embargo también debo señalar que en el periodo en que se ubican estos acontecimientos, los niños y sus padres frecuentemente desconocían su edad, por lo que el término no fue utilizado con precisión. Para el caso de los niños afrodescendientes, las denominaciones eran más amplias. Por ejemplo, los

1 Cristina Masferrer León, Muleke, negritas y mulatillos. Niñez, familia y redes sociales de los esclavos de origen africano en la ciudad de México, siglo XVIII. (México: Instituto Nacional de Antropología e Historia, 2013), 133.

2 Para la época se consideraba que un niño o niña era todo aquel que "no había llegado a los siete años de edad". Diccionario de Autoridades - Tomo IV [1734]. Consultado en https://apps2.rae.es/DA.html 
traficantes de personas esclavizadas denominaban mulekes a los niños procedentes directamente de África. Mientras que los niños nacidos en las Indias eran conocidos como "negrillo", "negrilla", "mulatillo" y "mulatilla". En este caso, el documento no precisa la edad de Diego: no obstante, he decidido tratarlo como un niño o al menos como una persona menor de diez años, ya que todos los testigos se refirieron a él como "mulatillo". ${ }^{3}$

\section{Presencia africana en Guatemala durante el periodo colonial}

Paul Lokken y Christopher Lutz señalan que los africanos llegaron al territorio que actualmente se conoce como Guatemala con el conquistador Pedro de Alvarado y con sus aliados indígenas procedentes del centro de México. ${ }^{4}$ Más tarde, la ciudad de Guatemala fue fundada en 1524 "en las inmediaciones de Iximché y luego fue trasladada a Almolonga en 1527”; sin embargo, no fue hasta el mes de marzo de 1543 cuando quedó formalmente establecida. ${ }^{5}$ A partir de entonces, la ciudad fue un centro político y económico para la región y su importancia perduró por casi tres siglos. Es por ello que desde su fundación se demandó mano de obra. Los primeros trabajadores fueron indios, pero debido a la mortandad originada por las epidemias esta población se redujo en un $80 \%$ y se requirió de trabajadores de origen africano para cumplir con las faenas. ${ }^{6}$

Otro factor determinante para la importación de un mayor número de africanos fue la introducción y desarrollo de nuevas empresas dedicadas a la producción de azúcar, cacao, trigo, añil, así como a actividades ganaderas, mineras y textiles, lo cual generó un aumento en la demanda de la mano de africana esclavizada. ${ }^{7}$ Sin embargo, a la par de estas actividades, los africanos y sus descendientes también se ocuparon del trabajo doméstico. Mujeres, varones y niños esclavizados fueron los encargados de realizar tareas tales

3 En el expediente una testigo de diez años aseguró que se había criado con Diego, sin embargo, esta afirmación no puede ser considerada como referente exacto para calcular la edad del mulatillo. De acuerdo con los datos proporcionados en el expediente se estima que Diego tenía aproximadamente de 6 a 10 años.

4 Paul Lakken y Christopher Lutz, "Génesis y evolución de la población afrodescendiente en Guatemala y el Salvador (1524- 1824)" en De olvido a la memoria. Africanos y afromestizos en la historia colonial de Centroamérica, Editora Rina Cáceres Gómez (Costa Rica: UNESCO, 2008), 16- 36.

5 Pablo Peña Vicenteño, "Relaciones interculturales. La Afroindianidad en la Audiencia de Guatemala. Siglos XVI, y XVII" (Tesis para obtener el grado de Maestro en Estudios Latinoamericanos, Universidad Nacional Autónoma de México, 2011), 43.

6 Lakken y Lutz, "Génesis y evolución”, 16.

7 Vicenteño, "Relaciones interculturales", 57. 
como cocinar, lavar, limpiar, amamantar, atender a algún enfermo o niño de la casa, etc.

En el ámbito doméstico, los africanos y sus descendientes esclavizados convivieron de manera más cercana con sus amos, del mismo modo que con otras personas de distintas calidades como indios, españoles y otras castas. No obstante, la cercanía con otras personas tuvo diversos matices: en ocasiones fue armoniosa y en otras conflictiva. Por ejemplo, algunas mujeres esclavizadas podían ser muy estimadas y protegidas por sus amas y en otras ocasiones eran víctimas de violencia corporal o sexual por parte de sus amos. En otros casos, los afrodescendientes establecieron lazos espirituales y de parentesco con otros sirvientes o habitantes de la casa en que residían. Por consiguiente, cada casa tenía una dinámica distinta, lo cual condicionaba la vida de sus moradores.

Los niños esclavizados en el ámbito doméstico experimentaron una diversidad de escenarios. Algunos de ellos vivían con ambos padres, pero la gran mayoría solo vivían con su madre; aunque la convivencia y corresidencia no estaba garantizada a largo plazo, la relación del niño y su madre estaba condicionada por las decisiones e intereses del amo. Dentro de este escenario nació, vivió y murió Diego, un mulatillo esclavizado de la ciudad de Santiago de Guatemala.

\section{La narración de los hechos}

El domingo 17 de septiembre de 1674, Juan Baptista de Urquila, oidor de la Corte, fue notificado de que en la casa de Don Hipólito de Porres y de Doña Francisca de Ocón se había ahorcado Diego, un mulatillo esclavizado. Ante el aviso, las autoridades fueron al lugar y encontraron:

un cuerpo de un mulatillo blanco, herrado en el rostro, colgado y pendiente de un cuero y un mecate que le señía la garganta, atado en dicho cuero, que este pendia de un clavo grande, que estava en una viga, y dicho cuerpo estava parado en el suelo, una rodilla cassi doblada, bestido con un pedasso de xerga, y unos calsones de paño, con una corma de palo, en el pie derecho ${ }^{8}$

Después de dar fe de los hechos, las autoridades ordenaron bajar el cuerpo de Diego para realizar una inspección. Lo desnudaron y retiraron la corma del pie. ${ }^{9}$ Los testigos observaron que bajo este instrumento de castigo se había

\footnotetext{
Archivo General de Indias (AGI), Escribanía 336 A, f. 1r.

9 Especie de cepo compuesto de dos pedazos de madera que se adaptan al pie de una persona o de un animal para impedir que ande libremente. Diccionario de la Real Academia Española. Consultado en: https://dle.rae.es/corma
} 
formado un callo grande, con lo cual conjeturaron que esa pieza llevaba bastante tiempo. A continuación, examinaron la espalda del niño y encontraron diversas cicatrices provocadas por los azotes. ${ }^{10}$

Después de la inspección, el alcalde hizo presentar a todas las personas cercanas a Diego. La primera en rendir su declaración fue llamada Melchora de los Reies, una "negrilla" esclavizada. La testigo comentó que sus amos salieron en la madrugada y dejaron la puerta de la casa cerrada con llave y que después vio que Diego comenzó a dar vueltas en el suelo mientras decía que le dolía el estómago y que se quería confesar. Por esta razón, decidió asomarse a la ventana para pedir ayuda. Dijo que primero vio a un clérigo, a quien le comentó lo que pasaba, pero como la puerta estaba asegurada, no pudo entrar. Entonces, Melchora pidió ayuda a un mulatillo que transitaba frente a la casa. Le dijo que fuese a la iglesia de San Francisco a llamar a su ama porque Diego se estaba muriendo. Después de enviar el mensaje, Melchora regresó al lado del niño y "le dio dos bofetadas dissiendo que era embuste, que no estava enfermo, y lo hiso sentar, y le dio un poco de chocolate y pan”. ${ }^{11}$ De acuerdo con el testimonio, Diego se restableció e iniciaron sus actividades domésticas. La niña expresó que el mulatillo le dijo que iría a barrer el cuarto de su amo; sin embargo, ella advirtió lo siguiente:

esta testigo le vio poner y colgar el cuero que pusso con una lanza desde sobre una caja y alli se amarró un mecate al cuello y se dejo caer, y aunque lo vio, tubo mucho miedo y por esso no ympidio el que se ahorcasse, ay aunque gritó no acudio nadie ni hubo como entrar porque estavan las puertas serradas y que quando bino su señora le dijo esta testigo, señora ya dieguillo se murio, con lo qual se alborotaron y llego mucha gente: y quando le dio el dolor de estomago se acuerda esta testigo que dijo este dolor de estomago tengo de los palos que me da [mi $]$ señora, yo me he de morir con mil diablos. ${ }^{12}$

Melchora se quedó atónita al presenciar el suicidio de Diego, y aunque gritó ningún habitante de la casa la escuchó. Después de narrar lo ocurrido, la testigo fue interrogada sobre la corma y respondió que Diego la llevaba por varios días. Además, informó que Diego constantemente recibía golpes por parte de su ama, llamada Doña Francisca, y de Antonia, una esclava de la casa. Sin embargo, de acuerdo con Melchora, los golpes que eran propinados por Antonia eran mucho más severos que los de la propia ama, ya que esta solía pegar a Diego con un palo en los dedos, espalda y pies; y en la boca usualmente lo hacía con un zapato. La testigo recordó que la última ocasión en que Diego había sido azotado fue por la pérdida de una canasta. Al concluir

10 AGI, Escribanía 336 A, f.1v-2r.

11 AGI, Escribanía 336 A, f. 2 v.

12 AGI, Escribanía 336 A, f. 3 r. 
su declaración, dijo "que aunque es esclava de dicha cassa, no por eso ha dejado de dessir verdad”, ${ }^{13}$ además que aseguró que no sabía su edad, pero el escribano registró que por su apariencia tenía catorce años.

Se presentó Francisca de Galbes, mulata libre y criada de doña Francisca y dijo que había llegado a la provincia del Soconusco hace seis meses y que desde entonces conocía a Diego. Expresó que desde que llegó a la casa, el mulatillo ya tenía herrado el rostro. Mencionó que le habían puesto la corma diez días atrás como castigo por la pérdida de un peso de pan y unos manteles. Después, testificó Antonia de la Asumsion [sic], “negrita” esclavizada de doña Francisca de Ocon. Indicó que conocía a Diego desde hacía mucho tiempo y que siempre había estado herrado en el rostro. También aseguró que había huido con una canasta de pan y unos manteles y como consecuencia, lo azotaron y le pusieron la corma. Del mismo modo que Melchora, Asumsión dijo que no sabía su edad, pero que el escribano consideró que por su apariencia tenía aproximadamente 16 años. A continuación, se presentó Ángela de Porres, esclavizada de la casa, quien dijo que había visto el nacimiento y crianza de Diego. Sobre él, comentó que había sido herrado del rostro porque había huido y que se le había puesto a trabajar en un obraje. Mencionó que Diego tenía buena vida porque lo cuidaban y le daban de almorzar; sin embargo, dijo que algunas veces lo oyó maldecir o afligirse. ${ }^{14}$ Posteriormente se presentó María, de calidad española de ocho años, quien comentó lo mismo Asumsión. A continuación, se interrogó a Lucrecia, india ladina, nacida y criada en casa de Doña Francisca. La mujer refirió que desde que Diego había sido azotado, su ama ya no lo dejaba salir. El último en rendir su testimonio fue Miguel Porres, quien se presentó como "un estudiante" y reveló que la última vez que le pegaron a Dieguillo habían sido 15 azotes.

Después rendir testimonio todos los esclavizados, sirvientes y habitantes de la casa, se presentaron Ramón de la Cruz, un mulato oficial de carpintero y Thomás de Peralta, un indio de oficio herrero, quienes declararon sobre cómo encontraron el cuerpo de Diego. Thomás de Peralta comentó que cuando le quitó la corma al niño:

de ella salian muchas chinches; y que dicho mulato tenía un callo grande abajo de donde estaba dicha corma, y este testigo quito dicha jerga de orden de su mersed, al cuerpo de dicho mulato para registrarlo, y vio este testigo las señales que tenia en la espalda, al lado derecho que parecian berdugones de asotes, que parese havía dias que se los havian dado ${ }^{15}$

13 AGI, Escribanía 336 A, f. 3v.

14 AGI, Escribanía 336 A, f. 6v.

15 AGI, Escribanía 336 A, f. 12r. 
Finalmente testificó doña Francisca, quien expuso los hechos ya descritos. Las declaraciones concluyeron, pero el 18 de septiembre del mismo año se presentó ante las autoridades Simona de los Santos, madre de Diego. Expresó que ella y sus hijos eran propiedad de Doña Francisca, pero indicó que los niños vivían en casa de su ama, mientras que ella trabajaba en una labor (propiedad de sus amos) en el valle de Misco [sic]. ${ }^{16}$ La mujer declaró que solo tenía noticias de sus hijos por medio de unos indios arrieros que le comunicaban que los niños "pasaban muchos trabajos de hambres y necesidades, y que los castigaban muy a menudo y con mucha crueldad la dicha doña Francisca asotandolos y mandandolos asotar, de lo qual sentia la susodicha mucho dolor y pesar". ${ }^{17}$

En su testimonio Simona narró con detalle el episodio que originó que calimbaran el rostro de su hijo. Comentó que un día Diego llegó a la labor y le dijo que había huido porque era continuamente azotado, no le daban de comer y además que había escuchado que sus amos lo querían herrar. La denunciante expresó que en ese momento revisó el cuerpo de su hijo y vio que tenía señales de que había sido golpeado. Por consiguiente, el niño permaneció a su lado hasta que llegó el alguacil mayor, y los condujo a un obraje, en donde Diego fue herrado en el rostro.

De acuerdo con el testimonio, Simona y su hijo laboraron en el obraje, sin embargo, ella permaneció menos tiempo que Diego ya que fue retirada para trabajar nuevamente en la labor. ${ }^{18}$ Una vez que concluyó la estadía del mulatillo en el obraje, este regresó a casa de sus amos en donde continuó siendo golpeado y pasando hambre; al mismo tiempo que era socorrido por unos indios arrieros que le daban tortillas a escondidas ya que lo veían "muy flaco". ${ }^{19}$ Finalmente, un día los indios le comunicaron a Simona que su hijo había muerto. Ella permaneció incrédula y quiso corroborarlo con el esposo de su ama, que se encontraba en la labor. Al ser interrogado, su amo le negó la noticia. Para salir de dudas, la mujer partió a la ciudad para comprobar los hechos y al enterarse de lo ocurrido decidió denunciar a sus amos ante las autoridades y solicitó el cambio de amo para ella y su hijo llamado Pedro Juan. La madre arguyó que requería otro propietario porque deseaba

16 La distancia del pueblo de Mixco a Santiago de Guatemala es de $7 \mathrm{~km}$.

17 AGI, Escribanía 336 A, f. 15v.

18 En el documento no se expresa el tiempo exacto que Diego y Simona permanecieron en el obraje.

19 AGI, Escribanía 336 A, f. 16r. 
proteger la vida del más pequeño, dado que antes de Diego ya había fallecido otro de sus hijos en casa de sus amos. ${ }^{20}$

Como respuesta a la denuncia, el 28 de septiembre del mismo año se emitió la sentencia que determinó que se debía dar la libertad a Simona; y más tarde, el 17 de octubre se indicó que Pedro Juan debía ser vendido a un precio moderado y en un plazo no mayor a quince días. Además, se indicó que el niño no podría volver "al dominio" de doña Francisca y su esposo. El veredicto fue contundente $y$, pese a que algunos criados aseguraron que sus amos proporcionaban buen trato, las autoridades consideraron que era intolerable el castigo que le habían dado a Diego, del mismo modo que calificaron el suicido del mulatillo como un "caso tan extraño de un esclabo que se quitó la vida tan ynjustamente”. ${ }^{21}$ De hecho consideraron

intolerable servicio a herrar y señalar en el rostro a los hombres y contra expresales de el reino que prohibe y manda que por ser el hombre hecho a semejanza de dios y no es justo que su ymajen se borre no se pueda poner pena de señalar en el rostro a los hombres si otro no se hiso por persona particular y contra ley yntorerable es pues lo posible el derecho de Castilla y assi lo que su ilustrisima con los esclabos que se adquieren por justa guerra en los reinos de guinea es marcales en otras partes del cuerpo para su conosimiento no en los rostro que es ynumanidad y lo que aun los jueses del Reino no pueden haser por enormes delitos menos sera lisito a los amos con sus esclabos por caseras culpas como es haverse huido un mucho sin salir de los alrededores de su casa de mas del castigo de un obraje y peor es mas casero con enserramiento priçiones de corma chinches tantos dias de hambre sed y desnudes sin mas cama ni abrigo que un cotonsillo de jerga y un calsonsillo que esto bastara durmiendo en el suelo $\mathrm{y}$ atareado en el hilado y repetidos asotes y palos $\mathrm{y}$ golpes en la boca y manos ${ }^{22}$

En la sentencia no se aprecia que los amos hayan recibido un castigo por los maltratos ocasionados a Diego. Sin embargo, resultó positiva para la madre ya que en compensación consiguió su manumisión, y cambio de amo para su hijo más pequeño.

\section{El trabajo de los niños esclavizados desde la experiencia de Diego}

La información proporcionada por el expediente presenta uno de tantos escenarios laborales en que trabajaban los niños esclavizados de origen africano en la ciudad de Guatemala y otras de Hispanoamérica. Se aprecia que

\footnotetext{
20 De acuerdo con las declaraciones de Simona, el primero de sus hijos había fallecido por falta de alimento y cuidado.

21 AGI, Escribanía 336 A, f. 37v.

22 AGI, Escribanía 336 A, f. 39r.
} 
Diego se dedicaba a las labores domésticas como barrer, hacer la limpieza general y los mandados de la casa al lado de otros niños y adultos de otras calidades. Sin embargo, tras huir de la casa para estar con su madre, ambos fueron castigados y enviados a laborar en un obraje. De este modo, el tipo de centro de trabajo cambió para la madre y su niño.

Aunque en el documento no se expresa el tipo de labor que realizaba Diego, solo nos resta especular sobre su nueva actividad. Dentro de un obraje los niños se podían ocupar de la limpieza, los mandados y el hilado. Por ejemplo, en Perú existen referencias de niños y adolescentes hiladores. Pese a su edad, estos trabajadores debían cumplir con largas jornadas de trabajo, además de que eran azotados en caso de no finalizar sus tareas. ${ }^{23}$ Aunado a estos tratos, hay que señalar que el ambiente en un obraje era extenuante. Los operarios debían cumplir con su labor en condiciones insalubres al mismo tiempo que padecían maltrato y eran mal alimentados. Por otro lado, el hacinamiento y las malas condiciones laborales generaron que las personas que trabajaban en estos sitios fueran proclives al amancebamiento, desarrollo de enfermedades y "otros pecados". ${ }^{24}$ Por lo cual, los dueños y encargados del lugar trataban de reprimir, castigar y corregir a los operarios por medio de malos tratos. Dicho lo anterior, el ambiente era tenso, estresante y peligroso para un niño pues estaba expuesto a cualquier clase de abuso físico o sexual por parte de sus compañeros de trabajo, sobre todo si consideramos que los obrajes no solo "eran la cárcel perfecta" ${ }^{25}$ para castigar a personas libres y esclavizadas, sino también un espacio punitivo en el que ingresaban cimarrones, cuatreros y maleantes para cumplir una pena. ${ }^{26}$

Ahora bien, el trabajo que se realizaba dentro de los obrajes fue regulado por ordenanzas desde mediados y finales del siglo XVI, pero no fue sino en el siglo XVII que las autoridades prohibieron el trabajo del indio y en consecuencia estos fueron reemplazados por africanos y sus descendientes, del mismo modo que por personas de otras calidades. ${ }^{27}$ No obstante, a pesar

23 Manuel Miño Grijalva, La protoindustria colonial hispanoamericana (México: Fondo de Cultura Económica, Colegio de México, 1993), 138.

24 Miño Grijalva, La protoindustria colonial hispanoamericana, 131.

25 Juana Patricia Pérez Munguía "La cárcel pública y los obrajes en la ciudad de Santiago de Querétaro en el siglo XVIII" en Africanos y afrodescendientes en la América Hispánica septentrional. Espacios de convivencia, sociabilidad y conflicto, coords. Rafael Castañeda y Juan Carlos Ruiz (México: Colegio de San Luis, 2020), tomo II, 573-597, 588.

26 Miño Grijalva, La protoindustria colonial hispanoamericana, 13; Carmen Bernard, Negros esclavos y libres en las ciudades hispanoamericanas (España: Fundación Histórica Talavera, 2001), 98.

27 Gonzalo Aguirre Beltrán, El negro esclavo en Nueva España. La formación colonial, la medicina popular y otros ensayos (México: Instituto Nacional Indigenista, Fondo de Cultura Económica, 1994), 75; Bernard, Negros esclavos y libres; Silvio Zavala, Ordenanzas del trabajo, siglos XVI y XVII (México: Universidad Nacional Autónoma de México, 1947), 
de las regulaciones, se tienen referencias de que para 1609 estaba permitido que hubiera indios "muchachos" como aprendices en los obrajes, y que estos gozaran de plena libertad. ${ }^{28}$ Esta permisividad se observa en los obrajes de Santiago de Querétaro, en Nueva España, donde había aprendices mayores de 11 años. ${ }^{29}$ Aunque cada espacio es distinto, se observa que en el caso del obraje en que estuvo Diego trabajaban personas de diferentes edades.

El trabajo de los niños africanos visto desde la vida de Diego muestra que este sector de la población se adaptaba a diferentes tipos de actividades en el hogar y fuera de él. Del mismo modo, su condición de trabajadores o esclavizados les impidió, como ocurre en este caso, convivir con su familia al mismo tiempo que los exponía a los malos tratos por parte de los adultos que se encontraban en su entorno. Así, por un lado, la actividad de los niños esclavizados y la de sus padres condicionaba la convivencia de la familia y, por el otro, la disposición del amo favorecía o impedía que los niños se relacionaran con sus padres como veremos en el siguiente apartado.

\section{Familia, relaciones sociales y labores de los niños esclavizados}

El modelo de la familia esclavizada fue distinto al tradicional y tuvo diversas características. ${ }^{30}$ Generalmente estas familias estaban integradas por la madre y los hijos; sin embargo, la convivencia del núcleo podía obstaculizarse por venta de uno de sus miembros o la separación por motivos laborales. En este sentido, las leyes u ordenanzas no regularon la convivencia entre padres e hijos. La iglesia únicamente protegió el vínculo del matrimonio pero nunca se opuso a la venta de los hijos procreados. ${ }^{31}$ Es decir, prevalecían lazos mercantiles sobre la unidad familiar. ${ }^{32}$

La ausencia de los progenitores ya sea por venta, distanciamiento laboral como el caso de Simona- y defunción, propició que algunos niños esclavizados desarrollaran un vínculo más estrecho con un adulto o niños del

181. El 4 de diciembre de 1602 se mandó que "no trabajen ni entren indios voluntarios ni forzados”. Después de los cuatro meses posteriores al mandamiento, los dueños de los obrajes debían proveerse de personas esclavizadas para el funcionamiento de los obrajes.

28 Recopilación de leyes de los reinos de las Indias: Tomo cuarto (Madrid: [1681]). Libro 6, ley 10. f. 150 .

29 Pérez Munguía “La cárcel pública y los obrajes”, 570.

so Masferrer León, Muleke, negritas y mulatillos, 207.

31 Asunción Lavrin, "La niñez en México e Hispanoamérica: rutas de exploración”, en La familia en el mundo iberoamericano, coord. Pilar Gonzalbo Aizpuru y Cecilia Rabell (México: Universidad Nacional Autónoma de México, Instituto de Investigaciones Sociales), 41-69.

32 Lavrin, "La niñez en México e Hispanoamérica”, 89. 
hogar en que habitaban. ${ }^{33}$ De igual modo, este escenario favoreció que algunos niños fueran más propensos a ser controlados, manipulados, explotados, engañados y violentados de manera física y sexual por parte de todas las personas de su entorno. ${ }^{34}$

La mano de obra infantil fue apreciada en el periodo colonial, aunque la venta de niños esclavizados fue menor en relación con la de personas de mayor edad. Para los amos, la compra representaba una inversión a largo plazo ya que los niños se adquirían a un bajo costo y con el paso del tiempo su valor se incrementaba. Sin embargo, también se exponían a perder su dinero debido al alto índice de mortandad infantil, por consiguiente, en la mayoría de los casos era conveniente la cercanía de la madre para lograr la supervivencia y crear lazos de parentesco al mismo tiempo que trasmitía la cultura entre sus descendientes..$^{35}$

El trabajo de los niños era diverso y en la medida en que iban creciendo el número de actividades aumentaba. En las ciudades algunos mulekes, negrillos y mulatillos eran considerados como un lujo o vanidad, ya que eran los pajes o acompañantes de la casa. ${ }^{36}$ Otros eran encargados de la limpieza, mandados y demás quehaceres domésticos en la casa, taller, iglesia, convento u hospital. Mientras que en el campo cuidaban de los animales, desyerbaban las siembras, limpiaban zanjas, recolectaban el cacao o el café y estiraban el tabaco. ${ }^{37}$

De acuerdo con los testimonios, se demuestra que en la casa donde vivía Diego habitaban personas de distintas edades, calidades y condiciones jurídicas, sin sus padres, y que cumplían con labores domésticas al mismo tiempo que realizaban competencias o juegos propios de su edad. ${ }^{38}$ De igual manera, se exhiben las redes sociales, vínculos de apoyo y solidaridad entre los mismos niños a partir de la convivencia diaria en el espacio doméstico. ${ }^{39}$

3s Masferrer León, Muleke, negritas y mulatillos, 207.

34 Ivette Pérez Vega, "El tráfico de niños esclavos en el sur de Puerto Rico" en Entre la familia, la sociedad y el Estado. Niños y jóvenes en América Latina (siglos XIX-XX), coords. Barbara Potthast y Sandra Carrera (Alemania: Editorial Iberoamericana, 2005) 25-49, 33.

35 María Elisa Velázquez, Mujeres de origen africano en la capital novohispana, siglos XVII y XVIII (México: Instituto Nacional de Antropología e Historia, 2006), 281; Masferrer León, Muleke, negritas y mulatillos, 273.

36 Pérez Vega, "El tráfico de niños esclavos", 33.

37 Pérez Vega, "El tráfico de niños esclavos", 35.

38 AGI, Escribanía 336 A, f. 7.

39 María Elisa Velázquez y Cristina Masferrer, "Mujeres y niñas eslavizadas en Nueva España: agencia, resiliencia y redes sociales" en Mujeres africanas y afrodescendientes: Experiencias de esclavitud y libertad en América Latina y África. Siglos XVI al XIX, coord. María Elisa Velázquez y Carolina González Undurruga (México: Instituto Nacional de Antropología e Historia, 2016), 49. 
Al respecto, Pilar Gonzalbo y Cecilia Rabell señalan que la coexistencia de niños de diversas calidades que vivían y trabajaban en hogares distintos a los suyos se debía a que algunas familias urbanas, que carecían de recursos económicos para hacerse cargo, cedían a sus hijos a otras familias para que estos aprendieran un oficio o trabajaran. ${ }^{40}$ En consecuencia, una proporción elevada de estos niños laboraron con personas esclavizadas. ${ }^{41}$

\section{Medidas de control y castigo}

Una de las medidas para controlar a los esclavizados fue el uso de golpes, calimbo y, en casos más graves, mutilaciones. Si bien las penas a este sector de la población fueron cambiando con el paso de los siglos, lo cierto es que los azotes fueron un castigo recurrente para niños y adultos. En este caso, en el expediente que trata sobre Diego se aprecia que en la casa eran golpeadas personas de diferentes edades y calidades. En el contexto de la época hay que subrayar que el uso de los golpes como medidas correctivas y punitivas estaba vigente para la población libre y esclavizada. Dentro del ámbito infantil, Dorothy Tanck señala que estas medidas se encontraban dentro de los reglamentos de algunas instituciones educativas. La autora señala que "tratar a los niños con amor y ternura no era la costumbre en muchas escuelas", ${ }_{42}$ pues en estos centros estaba permitido el castigo mediante golpes con sombreros de burro, alambres, pergaminos, cueros o mecates. ${ }^{43}$ Había casos en que se les ponía un collar redondo hecho de madera que obligaba al niño a permanecer derecho. En otros, el castigo consistía en meterlos en una bolsa, atarla y suspenderla en el aire por medio de dos cordeles. El propósito de estas medidas era exponer al estudiante ante todos sus compañeros. ${ }^{44} \mathrm{En}$ general los azotes eran parte de la manera en que se educaba y corregía a los niños.

En el caso de la población esclavizada el tipo de castigo era variable. Por ejemplo, a principios del siglo XVI la reglamentación sobre los esclavizados fugitivos consideró la castración o mutilación de alguna parte del cuerpo, sin embargo esta medida se modificó en 1540. La mutilación cambió a azotes y

40 Pilar Gonzalbo Aizpuru y Cecilia Rabell, "Diálogo abierto sobre la familia iberoamericana" en La familia en el mundo iberoamericano, Coord. Pilar Gonzalbo Aizpuru y Cecilia Rabell (México: Universidad Nacional Autónoma de México, Instituto de Investigaciones Sociales), 11.

41 Gonzalbo Aizpuru y Rabell, “Diálogo abierto sobre la familia iberoamericana”, 11.

42 Dorothy Tanck, "Muerte precoz. Los niños en el siglo XVIII" en Historia de la vida cotidiana en México. El siglo XVIII: Entre tradición y cambio, coord. Pilar Gonzalbo Aizpuru (México: Fondo de Cultura Económica, Colegio de México, 2005), 213-246, 227.

43 Tanck, "Muerte precoz", 227.

44 Tanck, "Muerte precoz", 227. 
su número estaba relacionado con las ocasiones que había tratado de huir. De este modo, si el esclavizado se había ausentado más de cuatro días recibía 50 azotes, en caso de que fuesen más días se le sujetaba con una calza de hierro. ${ }^{45}$ Ahora bien, las leyes no reglamentaron el número de azotes de acuerdo a la edad del esclavizado: únicamente se centraron en los días de ausencia. Posiblemente se consideró que las personas proclives a la fuga eran jóvenes y adultos. Entonces, ¿qué pasaba con los niños? Las leyes y ordenanzas sobre el tratamiento y castigo de las personas esclavizadas solo dan cuenta de los castigos, pero no se especifica la edad. En consecuencia, los párvulos se encontraron a merced de las decisiones de amos y adultos que estaban a su alrededor. El caso de Diego exhibe como algunos adultos abusaron de su autoridad e impusieron castigos muy rigurosos a los niños como lo fue la marca del calimbo.

El carimbo o calimbo generalmente fue usado para marcar a las personas esclavizadas al momento de su entrada a las Indias. Aunque esta práctica no siempre se llevó a cabo, es posible identificar algunas compañías que solían marcar a las personas esclavizadas llegadas de África. De este modo, encontramos adultos y niños marcados por los signos e insignias de las compañías tratantes. ${ }^{46}$ En otros casos la marca era utilizada por algunos propietarios para señalar a sus esclavos que tendían a fugarse. ${ }^{47}$ En este sentido, los amos de Diego consideraron que era conveniente hacer uso de esta marca debido a la "fuga". Sin embargo, en este contexto el uso del carimbo fue considerado excesivo ya que la partida del niño únicamente tenía la finalidad de ver a su madre. En ningún momento consideró huir completamente de su amo y convertirse en un cimarrón. ${ }^{48}$

De acuerdo con lo expresado en el juicio, las autoridades calificaron como excesivos e intolerables los castigos que recibió Diego ya que consideraron que herrar a una persona en el rostro era atentar a "la imagen y semejanza" de Dios con los hombres. ${ }^{49}$ Inclusive indicaron que aun en guerra justa

45 Ana María Zapata, El defensor de pobres como defensor de esclavos (1722-1839) (Argentina: Universidad Nacional del Sur, 2013), 65.

46 Maira Cristina Córdova A. "La marca del calimbo en cuerpos de africanos esclavizados de la ciudad de Antequera durante los siglos XVII y XVIII" en Los lenguajes de la historia. Oaxaca: siglos XVII- XX, coord. Selene García y Juan Manuel Yáñez (México:

Universidad Benito Juárez, Secretaria de las Culturas y Artes de Oaxaca, 2020), 33.

Existen referencias de que la compañía de Gran Bretaña marcaba a los africanos en su espalda izquierda y en los brazos.

47 Gonzalo Aguirre Beltrán, El negro esclavo en Nueva España. La formación colonial, la medicina popular y otros ensayos (México: Instituto Nacional Indigenista, Fondo de Cultura Económica, 1994), 42. El autor señala que en ocasiones los amos solían marcar a sus esclavos por vanidad.

48 Un esclavizado huido.

49 AGI, Escribanía 336 A, f. 39r. 
algunos africanos no eran marcados en el rostro, sino en diversas partes del cuerpo. Por lo tanto, la acción de doña Francisca y su esposo era ilícita dado que ningún amo podía marcar a su esclavizado en el rostro por "culpas caseras".50 Las apreciaciones de las autoridades estaban vigentes en ese momento, ya que para el año de 1674 aún no estaba permitido calimbar a los africanos esclavizados. Fue recién el 12 de marzo de 1685 cuando se autorizó su uso.

\section{La práctica del suicidio en la población esclavizada}

Durante el periodo colonial la mortandad infantil era muy elevada. Una cuarta parte de los niños moría antes de cumplir el primer año de edad y una otra lo hacía antes de cumplir los 10 años: por consiguiente, solo el 50\% llegaban a la adolescencia. ${ }^{51}$ Entre las causas más comunes para su deceso se encontraban las enfermedades, epidemias, atropellamiento, lesiones de peleas callejeras y accidentes como caídas de las azoteas, balcones y albarradas. ${ }^{52}$ En este sentido, se aprecia que la práctica del suicidio no era común entre la población infantil, o al menos, se conoce poco hasta el momento. ${ }^{53}$

El fenómeno del suicidio en la población esclavizada es un tema que ha ocupado a investigadores como Eugenio Fernández Méndez, Marisa Vega Franco, Gonzalo Aguirre Beltrán en México, Fernando Ortiz y Louis Pérez en Cuba. ${ }^{54}$ Los autores concuerdan en que el suicidio individual y colectivo era un síntoma de "hombres adultos, jóvenes y ancianos". ${ }^{55}$ En un primer momento, esta práctica preocupó a los traficantes de africanos ya que implicaba la pérdida de su capital o “mercancía”. Los esclavizados que decidían terminar con su vida en el trayecto del viaje trasatlántico se arrojaban al mar para morir ahogados. En este sentido, algunos pueblos africanos eran más proclives al suicidio que otros. Por ejemplo, Gonzalo

50 AGI, Escribanía 336 A, f. 39r.

51 Tanck, "Muerte precoz”, 223.

52 Tanck, "Muerte precoz”, 223.

53 Un artículo de Thomas Calvo refiere sobre el intento de una persona esclavizada sobre la tentativa de suicidio. Ver Thomas Calvo "Un drame personnel dans la trame historique: le tentative de suicide de lésclave Francisco de Paula à Guadalajara (1693)” en Penser l'Amérique au temps de la domination espagnole, Espace, temps et société, XVIe-XVIIIe siècle. Hommages à Carmen Val Julián, editores Pierre Bertha y Pierre Ragon (Francia: Ediciones L'Harmattan, 2001).

54. Elsa Malvido, "El suicidio entre los esclavos negros en el Caribe en general y en el francés en particular Una manera de evasión considerada enfermedad, siglos XVII y XVIII”, Travaux et Recherches dans les Amériques du Centre, 58 (2010): 113-124. Disponible en: https://journals.openedition.org/trace/1577? lang=fr

55 Malvido, "El suicidio entre los esclavos negros”, 117. 
Aguirre Beltrán señala que los Carabalí e Ibo eran más propensos a esta práctica. ${ }^{56}$

El suicidio de las personas esclavizadas ha sido interpretado como una resistencia en contra de los amos, pero en gran medida esta situación era provocada por diversos factores como miedo, ansiedad, desesperación, estrés permanente y depresión de la población esclavizada. ${ }^{57}$ Fernando Ortiz señala que la desesperación e impotencia por el maltrato físico, la imposibilidad de cumplir con la extenuante carga de trabajo, la soledad, el hambre, así como la separación de parientes originaron que, en su consternación, algunos cautivos decidieran terminar con su vida. ${ }^{58}$ Si bien esta práctica no se puede vincular exclusivamente a la población esclavizada, lo cierto es que hubo un segmento de dicha población que decidió concluir con su vida de este modo y recurrió a diversos métodos. De acuerdo con los registros relacionados con el suicidio durante el periodo colonial el ahorcamiento fue lo más común, sin embargo, hay casos en que los suicidas utilizaron armas punzocortantes como cuchillos, espadas y tijeras, además de envenenamiento y “precipitación”, a la cual fueron más proclives las mujeres. ${ }^{59}$

Para el caso de las personas esclavizadas, Elsa Malvido asegura que quienes recurrieron al suicidio eran personas jóvenes y adultas. ${ }^{60}$ Por consiguiente, este acto no está vinculado con la población infantil porque era poco frecuente o porque no ha sido estudiado a fondo hasta el momento tanto en Guatemala como en el resto de la Hispanoamérica. Es por ello que este caso es significativo dado que muestra cómo un niño decidió concluir con su vida tras maltratos, hambre y castigos que sobrepasaban su edad.

El suicidio de Diego muestra que la esclavitud urbana y doméstica, considerada en ocasiones como la más benévola o con jornadas de trabajo menos agotadoras y un mejor trato, también ofrecía escenarios hostiles para las personas esclavizadas de todas las edades. Al respecto, Colin Palmer señala que en este ámbito la servicia ${ }^{61}$ de algunos amos "llegó a abocar a los

56 Gonzalo Aguirre Beltrán, La población negra de México (México: Fondo de Cultura Económica, 1972), 135 y 187.

57 Malvido, "El suicidio entre los esclavos negros", 117.

58 Fernando Ortiz, "Fernando Ortiz: Tres aproximaciones al suicidio", Suicidio ¿'Tradición nacional?, Encuentro 45/46 (2007): 138.

59 Fernando Ortiz, "Fernando Ortiz: Tres aproximaciones al suicidio", 138. José Edgar Nieto Arizmendi, "El suicidio en Nueva España" (Tesis para obtener el grado en Historia, Universidad Nacional Autónoma de México, 2019), 122.

60 Malvido, "El suicidio entre los esclavos negros", 117.

${ }_{61}$ Se le conoce como servicia a la excesiva crueldad que ejercían algunos amos sobre sus esclavos. 
más desventurados al suicidio". ${ }^{62}$ Por consiguiente, se ha especulado que la población esclavizada desarrolló prácticas controvertidas y autodestructivas como la ebriedad, automutilaciones y suicidio para evadir y resistir las jornadas de trabajo extenuante, lo cual, a la larga, les generó un estereotipo negativo. ${ }^{3}$

Pese a que la esclavitud estuvo regulada por leyes y ordenanzas que tenían el propósito de estipular los derechos y obligaciones de las personas sujetas a servidumbre, los testimonios documentales arrojan información que demuestra que algunos amos tomaron criterios personales y prácticas punitivas excesivas para dirigir la vida y trabajo de sus esclavos. ${ }^{64}$

Aunque las personas esclavizadas que habitaban en dominios de la Corona española tenían la posibilidad de quejarse ante las autoridades sobre los maltratos ejercidos por sus amos, esto no siempre ocurrió, sobre todo si se considera que algunos vivían en lugares apartados a las instancias judiciales o no podían salir de su centro de trabajo. En el caso de Diego se muestra que, aunque el niño vivía en la ciudad, su madre no denunció los hechos hasta el deceso de su hijo; pero una vez interpuesta la denuncia, esta fue atendida por las autoridades, que brindaron una sentencia favorable a la pequeña familia.

\section{Consideraciones finales}

El análisis del caso de Diego expone las vicisitudes que enfrentaban los niños de origen africano esclavizados en ciudades de Hispanoamérica. En primer lugar, se muestra que los vínculos de la familia esclavizada eran frágiles y aunque la venta haya ocurrido en conjunto, no aseguraba la convivencia y corresidencia de la madre y sus hijos. Por consiguiente, los lazos mercantiles se encontraban por encima de los lazos afectivos entre padres y su descendencia. El ejemplo de la familia de Simona muestra como cada unidad

62 Bernard, Negros esclavos y libres, 97; Maribel Arrelucea Barrantes, Sobreviviendo a la esclavitud. Negociación y honor en las prácticas cotidianas de los africanos y afrodescendientes. Lima 1750-1820 (Perú: Instituto de Estudios Peruanos, 2018), 339; Carlos Aguirre, Breve historia de la esclavitud en Perú. Una herida que no deja de sangrar (Perú: Fondo Editorial del Congreso de Perú, 2010), 96. Carlos Aguirre señala que el trabajo en las panaderías era una práctica punitiva aceptada por la sociedad limeña. El trabajo en estos centros se considera extenuante, ya que los trabajadores debían trabajar jornadas muy largas, bajo el calor de los hornos y la amenaza del castigo. Algunas de ellas contaban con toda una serie de enseres de una cárcel como grilletes, cadenas, cepos y látigos.

63 Arrelucea, Sobreviviendo a la esclavitud, 167; Arrelucea señala que algunos esclavizados optaron por esta actitud para disminuir su carga laboral o el monto de sus jornales.

64 Velázquez y Masferrer, "Mujeres y niñas eslavizadas en Nueva España”, 54. 
familiar esclavizada en las Indias lidiaba con una infinidad de situaciones adversas, que en ocasiones podían ser dirimidas por las instituciones legales.

La resistencia y resiliencia eran dos actitudes que adoptaban algunos esclavizados ante jornadas laborales extenuantes, maltratos y separaciones de sus seres queridos. En el caso de la resistencia, a veces ocurría de manera violenta o evasiva como en los casos de enfrentamientos y el cimarronaje. En otros, se llevaba a cabo por medio de conductas autodestructivas, llegando hasta el suicidio como en el caso de Diego. En cambio, la resiliencia fue una conducta que les permitió a los afrodescendientes esclavizados sortear o superar circunstancias difíciles o traumáticas como los abusos y maltratos. Así algunos buscaron una vida mejor por medio de la denuncia ante las instancias judiciales.

En el caso analizado se aprecia que, aunque la Corona española brindaba el espacio legal para las personas esclavizadas, algunas de ellas no denunciaban debido a la tolerancia excesiva, impedimento para salir de sus centros de trabajo para acudir a las instancias judiciales. Por otro lado, se observa la importancia de las redes de apoyo, lazos de solidaridad y vínculos de amistad entre indios y afrodescendientes en el ámbito rural y urbano.

La sentencia dada por las autoridades buscó constituir un ejemplo para la posteridad en la ciudad, y si bien la medida afectó de manera exigua a los amos, se tradujo en la pérdida de su mano de obra o de su inversión tras haber concedido gratuitamente la libertad a Simona. Finalmente, el suicidio de Diego demostró, por un lado, el castigo excesivo de algunos amos, y por el otro, que no todos los esclavizados pudieron contener las circunstancias adversas que enfrentaban día a día, pues, aunque el niño tuvo un círculo de apoyo, requirió de la cercanía de su madre. De la misma manera que Diego, muchos niños esclavizados fueron vulnerables -sobre todo ante la ausencia de sus padres-, y es posible que fallecieran por los golpes y azotes propinados por sus amos u otros compañeros de trabajo o vivienda y que no haya quedado testimonio escrito de ello debido a la falta de denuncia u ocultamiento de este tipo de hechos por los mismos amos, capataces o encargados. 
Title: Reflections on the Domestic Work of an Enslaved Child in Santiago de Guatemala, 1674.

Abstract: This article analyzes the working and family conditions experienced by some children of African origin in Latin America. It assesses the work and suicide of Diego, an enslaved boy from the city of Santiago de Guatemala in the second half of the seventeenth century. Drawing on Diego's case, the goal of the paper is to raise various issues related to daily life and mistreatment experienced by some enslaved children in their homes and workplaces. On the one hand, it explores the family and work structure of children subject to servitude. On the other, it addresses the issue of coexistence and vulnerability relationships of these enslaved children with their master, co-workers and adults with whom they lived.

Keywords: slavery, childhood, calimbo, suicide, Guatemala

Título: Reflexões sobre o trabalho doméstico de uma criança escravizada em Santiago de Guatemala, 1674.

Resumo: O objetivo do artigo é analisar as condições de trabalho e familiares vividas por algumas crianças de origem africana na América Latina. Trata da obra e do suicídio de Diego, um menino escravo da cidade de Santiago da Guatemala na segunda metade do século XVII. O objetivo da análise é levantar várias questões relacionadas ao cotidiano e aos maus-tratos vividos por algumas crianças escravizadas em suas casas e locais de trabalho a partir do caso de Diego. Por um lado, analisa-se a estrutura familiar e de trabalho em que se encontravam os filhos sujeitos à servidão. Por outro lado, aborda-se a questão das relações de convivência e vulnerabilidade dessas crianças escravizadas com seu mestre, colegas de trabalho e adultos com quem conviveram.

Palavras-chave: escravidão, infância, calimbo, suicídio, Guatemala 